\title{
FUNCTIONAL OUTCOME OF LOCKING COMPRESSION PLATE OSTEOSYNTHESIS IN SCHATZKER'S TYPE V AND VI TIBIAL PLATEAU FRACTURES
}

\author{
Deependra Sonkar1, Akhil Bansal2, Jiten Shukla33, Sanjeev Gaur ${ }^{4}$ \\ ${ }^{1}$ Assistant Professor, Department of Orthopedics, Gandhi Medical College, Madhya Pradesh. \\ ${ }^{2}$ Assistant Professor, Department of Orthopedics, Gandhi Medical College, Madhya Pradesh. \\ 3 Professor \& HOD, Department of Orthopedics, Bundelkhand Medical College, Madhya Pradesh. \\ ${ }^{4}$ Professor \& HOD, Department of Orthopedics, Gandhi Medical College, Madhya Pradesh.
}

\begin{abstract}
Tibial plateau fractures are the common injuries that may be associated with poor outcomes and a high rate of complications. The problem rise significantly in high energy trauma and severe soft tissue injuries. Early technique of osteosysnthesis were based on extensive surgical approach. Introduction of minimally invasive plate osteosynthesis using locking compression plate conserves the vascularity of the bone but also leads to the overall improvement in the values of bone healing.

MATERIALS AND METHODS: Inclusion criteria for this study were patients of either sex, tibial plateau fractures Schatzker's Type V and VI, age group 15 to 60 years and compounding upto Gustilo and Anderson's Grade II and excluded the patients where the compounding was grade III and displacement $<2 \mathrm{~mm}$. The fractures were treated applying LCP percutaneously either medially or laterally depending on the side of comminution.

RESULTS: In our study conducted on 45 patients 4 lost to follow up in first 6 months with displaced tibial plateau overall the functional result using Rasmussen's criteria was acceptable in all of the cases with an average score of 26.38. All the patients in our series showed union with average time for union being 13.3 weeks.

DISCUSSION: Our study confirms that minimally invasive locking compression plate osteosynthesis is a viable alternative as a treatment for open tibial plateau fractures Gustilo and Anderson's type I and II. The incidence of infection in our study wad 10\% which is comparable with most of the series in literature that select the high energy tibial plateau fractures. None of the patients had nonunion only one had delayed union and does not required bone grafting as the metaphyseal area has a good blood supply. There were superficial infection in 4 cases which resolved to the dressing and antibiotic treatment within 3 weeks. The mean range motion at knee joint was 5 degree to 130 degree.(1)

CONCLUSION: This paper reports the short term results of utilization of the LCP for high-energy tibial plateau fractures. The early results have been good with excellent restoration of knee stability and motion and minimal soft tissue complications. The LCP effectively addresses the problems of alignment associated with fractures of the tibial plateau Schatzker's Type V and VI. We recommend LCP fixation as a treatment for severe tibial plateau fractures based on our results to date.
\end{abstract}

KEYWORDS: Locking Compression Plate, Schatzker's Type V and VI Fractures.

HOW TO CITE THIS ARTICLE: Deependra Sonkar, Akhil Bansal, Jiten Shukla, Sanjeev Gaur. "Functional Outcome of Locking Compression Plate Osteosynthesis in Schatzker's Type V and VI Tibial Plateau Fractures ". Journal of Evolution of Medical and Dental Sciences 2015; Vol. 4, Issue 89, November 05; Page: 15450-15454, DOI: 10.14260/jemds/2015/2207.

INTRODUCTION: Tibial plateau fractures are the common injuries that may be associated with poor outcomes and a high rate of complications. The problem rise significantly in high energy patterns such as Bicondylar fractures and fractures with metaphyseal or diaphyseal component. Severe soft tissue injury and complications arising from the damaged soft tissue are also the major cause of poor outcomes following tibial plateau fractures.

Early technique of osteosysnthesis emphasized anatomical reduction and rigid fixation of fractures. Surgical approaches were often added to the soft tissue damage already present from the injury. $(2,3,4,5,6,7,7,8,9,10)$

There has been a recent trend toward surgical fixation of high energy tibial plateau fractures utilizing minimal invasive technique.(11,12,13,3,14,15)

Financial or Other, Competing Interest: None.

Submission 15-09-2015, Peer Review 16-09-2015,

Acceptance 01-10-2015, Published 05-11-2015.

Corresponding Author:

Dr. Akhil Bansal,

Assitant Professor,

Department of Orthopedis,

Gandhi Medical College, Madhya Pradesh.

E-mail:drbansal_2001@yahoo.com

DOI: $10.14260 /$ jemds/2015/2207.
The superiority of minimally invasive plate osteosynthesis in maintaining arterial vascularity and perfusion in cadaveric femur is well documented. The biologic fixation not only conserves the vascularity of the bone but also leads to the overall improvement in the values of bone healing.(16,17) The early results reported using are very encouraging. However because of the need of close reduction technique, these techniques are technically demanding. There also associated risk of malalignment. Our hypothesis is that the fixed angle LCP provides adequate stabilization for bicondylar tibial plateau fractures without additional stabilization of the second border of the tibia.

MATERIALS AND METHODS: Inclusion criteria for this study were patients of either sex, tibial plateau fractures Schatzker's Type V and VI (21), age group 15 to 60 years and compounding upto Gustilo and Anderson's Grade II and excluded the patients where the compounding was grade III and displacement $<2 \mathrm{~mm}$. The fractures were treated applying LCP percutaneously.(16) either medially or laterally depending on the side of comminution. $(2,13,3,4,5,18)$

SURGICAL TECHNIQUE: The technique of osteosynthesis with LCP allows minimal invasive approach.(16) to the soft tissue. A limited surgical approach consisting of a curved 
incision over the proximal lateral or medial aspect of the tibia depending on which side the plate has to be applied was performed. The articular portion of the tibial plateau was reduced and stabilized as needed with wires or screws. Prior to placing the LCP, the fracture was reduced and evaluated under fluoroscopy.

A submuscular plane was developed under the anterior compartment muscle and the LCP was then slide under the muscles. After evaluating the location of the plate both clinically and radiologically, the LCP was pinned to the tibia proximally and distally after checking the reduction. When the surgeon was satisfied with the quality of the reduction, the fracture was then stabilized with LCP screws. These are the self-tapping screws with threaded heads that lock into the plate. All the screws were bicortical.

RESULTS: This is a prospective study conducted on 45 patients with displaced tibial plateau fractures $(>2 \mathrm{~mm})$ attending the department of Orthopaedics and Traumatology, Gandhi medical college, Bhopal between January 2009 to December 2012. Out of 45 patients 4 patients were lost to follow up during the $1^{\text {st }} 6$ months of the study. Hence the final study comprises of 41 patients. The average age group of the patients was 39.38 yrs.(18) The male (3:1) out numbered the females by almost three times. Both sides were almost equally involved. Road traffic accidents were the most common mode of injury.(12,19,20,15) of the 41 cases 3 were having grade I compounding and 7 were having grade II compounding with 31 non-compound patients having displaced $(>2 \mathrm{~mm})$ tibial plateau fractures were treated operatively using locking compression plate for internal fixation. Patients were followed at monthly interval.

The mean follow up was 37.8 months (18 months to 6 years). At 60 month follow up the mean range of motion was 5 degrees to130 degrees with 5 degrees loss of extension.(1) The mean Rasmussen's score was 26.38.(17) Quality of reduction in depressed plateau fractures was excellent in $61 \%(<2 \mathrm{~mm})$, satisfactory in $34 \%$ ( 2 to $5 \mathrm{~mm}$ ) and poor in $5 \%$ $(>5 \mathrm{~mm})$ at 6 month follow up.(5) Overall the functional result using Rasmussen's criteria.(21,9) was acceptable in all of the cases with an average score of 26.38. All the patients in our series showed union with average time for union being 13.3 weeks. ${ }^{(11,12,2)}$

\section{Sex Ratio:}

\begin{tabular}{|c|c|c|}
\hline Sl. No. & Sex & No. of Patients \\
\hline 1 & MALE & 31 \\
\hline 2 & FEMALE & 10 \\
\hline \multicolumn{2}{|c|}{ Table 1: Majority of the patients were male(3:1) } \\
\hline
\end{tabular}

Males were almost three times more commonly affected.

\begin{tabular}{|c|c|c|}
\hline $\begin{array}{c}\text { Sl. } \\
\text { No. }\end{array}$ & $\begin{array}{c}\text { Gustilo and Anderson's } \\
\text { classification }\end{array}$ & $\begin{array}{c}\text { No. of } \\
\text { Patients }\end{array}$ \\
\hline 1 & NON COMPOUND & 31 \\
\hline 2 & GRADE I COMPOUND & 3 \\
\hline 3 & GRADE II COMPOUND & 7 \\
\hline \multicolumn{3}{|c|}{ Table 2: Non-Compound/Compound } \\
\hline
\end{tabular}

Majority of the patients had non-compound injuries.

\begin{tabular}{|c|c|c|}
\hline Sl. No. & Type of Tibial plateau & No. of Patients \\
\hline 1 & TYPE V & 11 \\
\hline 2 & TYPE VI & 30 \\
\hline \multicolumn{3}{|c|}{ Table 3: Type of Tibial Plateau Fractures } \\
\hline
\end{tabular}

Majority of the patients had type VI tibial plateau fracture.(2)

\begin{tabular}{|c|c|c|}
\hline Sl. No & Age Group & No. of Patients \\
\hline 1 & $0-10$ YEARS & 0 \\
\hline 2 & $10-20$ YEARS & 0 \\
\hline 3 & $20-30$ YEARS & 5 \\
\hline 4 & $30-40$ YEARS & 26 \\
\hline 5 & $40-50$ YEARS & 6 \\
\hline 6 & $50-60$ YEARS & 4 \\
\hline \multicolumn{2}{|c|}{ Table 4: Age Distribution } \\
\hline
\end{tabular}

Most common age group was $30-40$ years with the mean age of 39.27 years mainly the bread earners of the family.(10)

\begin{tabular}{|c|c|c|}
\hline Sl. No. & Functional Criteria & No. of Patients \\
\hline 1 & POOR & 0 \\
\hline 2 & FAIR & 0 \\
\hline 3 & GOOD & 14 \\
\hline 4 & EXCELLENT & 27 \\
\hline \multicolumn{2}{|c|}{ Table 5: Functional Result according to Rasmussen's } \\
Criteria
\end{tabular}

All the patients had acceptable Knee function according to the Rasmussen's Functional Criteria.(21,9)

\begin{tabular}{|c|c|c|}
\hline Sl. No. & Complications & No. of patients \\
\hline 1 & HARDWARE PROMINENCE & 4 \\
\hline 2 & SUPERFICIAL INFECTION & 3 \\
\hline 3 & PLATE BREAKAGE & 1 \\
\hline 4 & PLATE EXPOSURE & 2 \\
\hline 5 & NON-UNION & 0 \\
\hline \multicolumn{2}{|c|}{ Table 6: Complications } \\
\hline
\end{tabular}

4 patients had hardware prominence where the plate was applied on the medial side, 3 had superficial infection, 2 had plate exposure, 1 had plate breakage. 

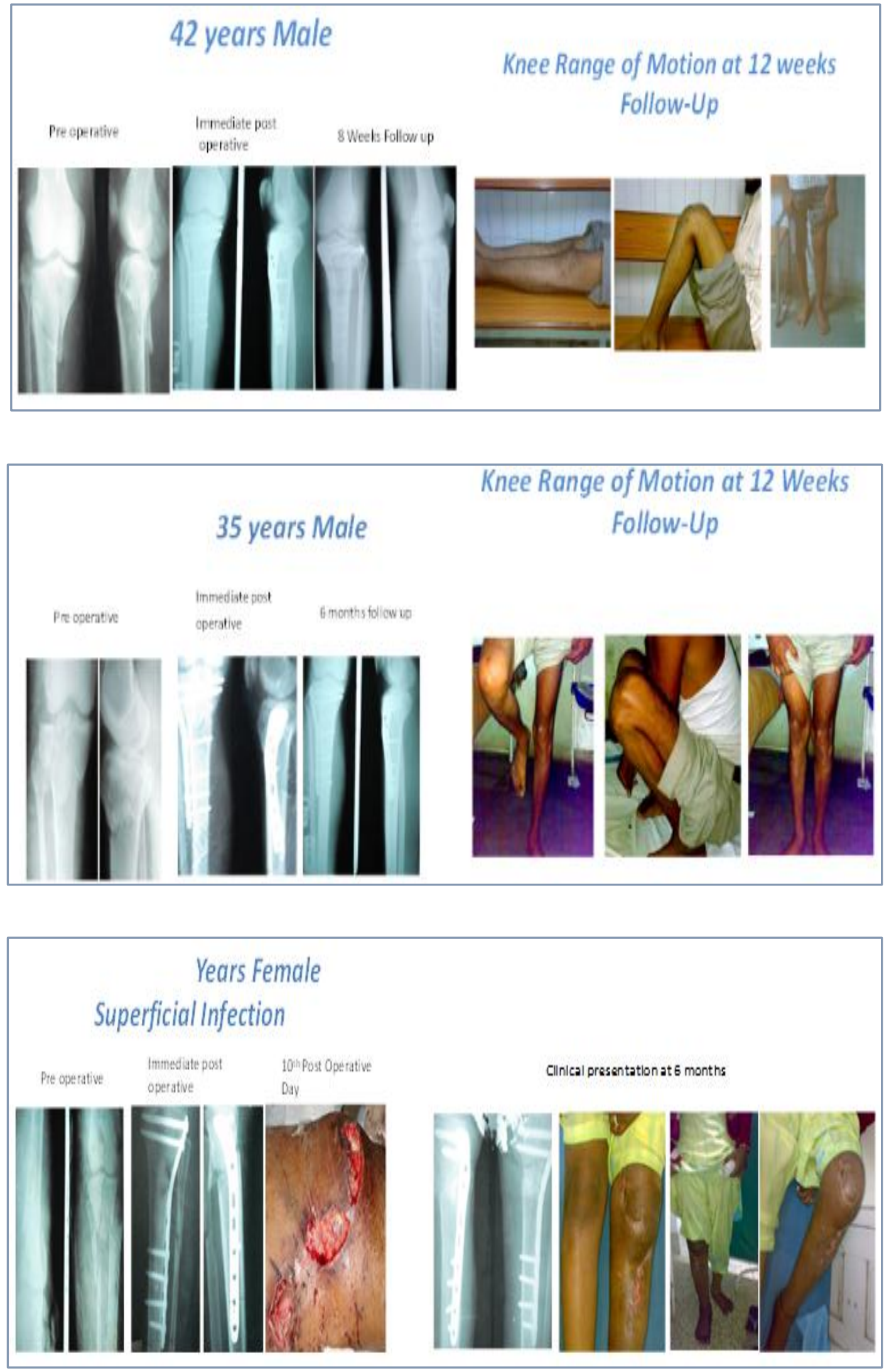

DISCUSSION: High energy tibial plateau fractures are severe injuries frequently associated with multisystem trauma, ipsilateral skeletal trauma and multi-ligamentous injuries. The results of treatment of these injuries have often been poor with loss of motion, instability, post traumatic osteoarthiritis, wound breakdown and infection as full outcome. When high energy fracture patterns are selected for independent analysis, unsatisfactory results are reported. Deep infection and osteomyelitis remain the significant problem with the rates of $80 \%$ or more.

Management of unstable tibial plateau fractures by plaster cast immobilization has always been difficult and can 
often lead to fracture displacement and eventually unsatisfactory results. Reduced mobility by plaster cast in the early post-injury period also makes them highly risky for developing a deep vein thrombosis. On the other hand, the traditional form of open reduction and internal fixation has a incidence of soft tissue problems. Minimally invasive technique fall in between these two methods of management and have gained popularity over the recent years.

Percutaneous screw fixation with elevation of the depressed tibial joint surface has been associated with good results. It is recommended these fractures should be treated by open reduction and fixation as they have tendency to drift in varus. It was therefore, felt that percutaneous screws alone would be inadequate. Numerous recent papers have described the use of conventional hybrid and small wire circular external fixation.

There has been a marked decrease in the incidence of soft tissue breakdown and infection with the use of external fixation, although it has not been eliminated, and septic arthritis has become more common with this technique, with the incidence of 4 to $10 \%$. Varus or valgus malalignment have both been noted following external fixation. Delayed union, nonunion, loss of motion, ankylosis, infection, pin tract infection, instability and failure in clinical assessment have all been reported, and treatment may last ten to seventeen weeks.

Reports of minimally invasive techniques with energy fracture type are very limited to date. The MIPO technique was superior in preserving the blood supply to the bone in all vessels when compared with open plating. Collinge et al have published a retrospective review of high energy articular or periarticular tibial fractures. Fourteen patients were available for follow up. There were no malunions and only one patient developed osteomyelitis.

The LCP system a new concept in plate osteosynthesis that attempts to combine the advantages of minimally invasive surgical approaches utilizing anatomically preshaped plates that with screws that lock into the plate forming the fixed ankle device. The LISS combined with indirect reduction technique limits the surgical trauma inflicted while stabilizing the fracture. The locking screws provide a fixed angle device at each screw plate interface.

The stability provided by such a construct allows treatment of unstable tibial plateau fractures with a single laterally or medially based LCP plates that previously required either medial and lateral plates a circular external fixators, or a combination of plates and an external fixator. The tibial LCP offers a solution to the problem of malalignment that is simple and effective. The plate is placed with the knee in a semi-extended position, and the fixed angle screws prevent late displacement of the reduced fracture.

Severe soft tissue injuries and open fractures are common with high energy tibial plateau fractures. Most authors have utilized external fixation as the treatment of choice following open tibial plateau fractures. Several authors have noted that percutaneous plating technique have allowed the use of plate osteosynthesis in the presence of open fractures. Their results with indirect reduction and minimally invasive surgical techniques have yielded infection rates no higher than those reported with external fixation.

Our study confirms that minimally invasive locking compression plate osteosynthesis is a viable alternative as a treatment for open tibial plateau fractures Gustilo and Anderson's type I and II. The incidence of infection in our study wad $10 \%$ which is comparable with most of the series in literature that select the high energy tibial plateau fractures. None of the patients had nonunion only one had delayed union and does not required bone grafting as the metaphyseal area has a good blood supply.

There were superficial infection in 4 cases which resolved to the dressing and antibiotic treatment within 3 weeks. The mean range motion at knee joint was 5 degree to 130 degree. $(21,9)$ This study has some obvious shortcomings that limits the conclusion. The most obvious weakness is short follow-up.

CONCLUSION: High-energy tibial plateau fractures are severe injuries with a high risk of complications and poor outcomes. They are frequently associated with open fractures or severe injury to the soft tissue envelope. Traditional methods of plate osteosynthesis have been associated with a high rate of complications. New methods of percutaneous plate osteosynthesis have been developed and are associated with decreased infections and soft tissue complications without use of bone grafting in the metaphyseal region. ${ }^{(12,3,4)}$ The LCP incorporates the advantages of minimally invasive techniques with fixed angle device.

This paper reports the short term results of utilization of the LCP for high-energy tibial plateau fractures. The results have been good with excellent restoration of knee stability and motion and minimal soft tissue complications. The LCP effectively addresses the problems of alignment associated with fractures of the tibial plateau Schatzker's Type V and VI. We recommend LCP fixation as a treatment for severe tibial plateau fractures based on our results to date.

\section{REFERENCES:}

1. Delamarter, R.,and Hohl ,M.: The cast brace and tibial plateau fractures. . Clin Orthop Relat Res. 242:26-31, 1989.

2. David P Barei, MD , FRCS(c), SeanE.Nork MD, Williiam J. Mills, Chad P. Coles, M.Bradford Henley, and Stefen K. Benirschke; Functional outcome of severe Bicondylar Tibial plateau fractures Treated with dual Incision and Medial Lateral Plates. The journal of bone and joint Surgery. Inc 2006.

3. Gosling, T MD; Schandelmaier P, Marti A, hufner T, Partenheimer A, Krettek C. Less invasive stabilization of complex tibial plateau fractures: a biomechanical evaluation of a unilateral locked screw plate and double plating, J Orthop Trauma 2004.

4. Gosling, T MD ; Schandelmaier, P MD; Muller, M MD; Hankemeier, S MD ; Wagner , M MD Krettek, C FRACS Single Lateral Locked Screw Plating of Bicondylar Tibial Plateau Fractures. Clinical Orthopaedics and Related Research.

5. Higgins TF, Klatt J, Bachus KN Biomechanical analysis of bicondylar tibial plateau fixation: How does lateral locking plate fixation compare to dual plate fixation? J Orthop Trauma may 2007.

6. Partenheimer A, Gösling T, Müller M, Schirmer C, Kääb M, Matschke S, Ryf C, Renner N, Wiebking U, Krettek C Management of bicondylar fractures of the tibial plateau with unilateral fixed-angle plate fixation Unfallchirurg. 2007. 
7. Pual F. Lachiewicz, Thomas Funcik: Factors influencing the results of open reduction and internal fixation of Tibial plateau fractures: Clin. Orthop. October 1990; 259:210-15.

8. Phisitkul P, McKinley TO, Nepola JV, Marsh JL. Complications of Locking plate fixation in complex proximal tibia injuries J. Orthop. Trauma. 2007.

9. Ractcliff JR, Werner FW, Green JK, Harley BJ; Medial buttress versus lateral locked plating in a cadaver medial tibial plateau fractures model; J. Orthop. Trauma. 2007.

10. Young MJ, Barrack RL, Complications of internal fixation of tibial plateau fractures, Orthop Rev. 1994 Feb;23(2):149-54.

11. Christoph Sommer, Emanuel Gautier, Matthias Muller, David L.Helfet, Michael Wagner, First Clinical Results Of the Locking Compression plate(LCP) Injury. Int.J.CareInjured 34(2003) S-B43-B54.

12. Cole, Peter A. MD, Zlowodzki, Michael MD ; Kregor, Philip J MD ; Treatment of proximal Tibial Fractures using the Less Invasive Stabilization System: Surgical Experience and Early Clinical Results in 77 Fractures. Journal of Orthopaedic Trauma 2004.

13. Egol KA, Su E, Tejwani NC, Sims SH, Kummer FJ, Koval $\mathrm{KJ}$; Treatment of Complex tibial plateau fractures using the less invasive stabilization system plate: clinical experience and alaboratory comparission with double plating; J Trauma 2004 Aug (2): 340-6.
14. Rucci, William M, Rudzki, Jonas R, Borrelli Joseph; Treatment of Complex Proximal Tibial Fractures with the less invasive stabilization system J. Orthop. Trauma. 2004.

15. Stannaard J P, et al, The Less Invassive stabilization system in the treatment of complex fractures of the tibial plateau: short term results. J. Orthop. Trauma. 2004.

16. Michael Wagner General principles for the clinical use of the LCP. Injury .Int. J.

Care Injured 34 (2003) S-B31-S-B42.

17. Raschke, Michael, Stange Richard, Vordemvenne, Thomas, Frerichmann, Uwe, Fuchs, Thomas; Locked Plating: Biomechanics and Biology and Clinical indications Techniques in Orthopaedics 2007.

18. Lee JA, Papadakis SA, Moon C, Zalavras CG: Tibial plateau fractures treated with the less invasive stabilization system; Int. Ortho. 2007 Jun; 31(3):415-18.

19. David J Hak The use of Osteoconductive Bone graft Substitutesin Orthopaedics trauma; J Am Acad Orthop Surg. Vol 15, No 9, September 2007, 525-53.

20. Rasmussen Poul, S., Tibial condylar fractures: impairment of knee joint stability as an indication for surgical treatment. Journal of Bone and Joint Surgery Am. Oct. 1973,55-A,No.7:1331-50.

21. Poul S. Rasmussen M.D. Gothenburg Sweden, Tibial Condylar Fractures, the Journal of Bone and Joint Surgery American Volume October 1973. 